Indonesian Journal of Medicine (2019), 4(3): 192-200

https://doi.org/10.26911/theijmed.2019.04.03.01

\title{
The Effect of Changes in Postural Position Angle Degree on Central Venous Pressure Measurement
}

\author{
Hendy Lesmana'), Maria Imaculata Ose'), Rahmatuz Zulfia'1), \\ Kurniaty Ika Sari Tobing2) \\ 1)Nursing Department, Faculty of Health, Universitas Borneo Tarakan \\ ${ }^{2)}$ Intensive Care Unit of Tarakan Hospital, North Kalimantan
}

\begin{abstract}
Background: Central venous pressure is often used in intensive care, especially in patients who experience impaired fluid balance, heart failure, evaluation of therapeutic response and media for therapy or hypertonic fluid. The patient's hemodynamic condition during treatment in the intensive care unit (ICU) is constantly changing (unstable), therefore, serial monitoring of central venous pressure is needed and the patient's position must be constant. Changing the position of the patient in a place is sometimes something that cannot be avoided when the patient is in intensive room. This study aimed to examine the effect of changing the position of patients in bed at $0^{\circ}, 15^{\circ}$, $30^{\circ}$, and $45^{\circ}$ on central venous pressure (CVP) values.

Subjects and Method: This was quasi-experimental study, using a post test without control group with repeated measures. This study was conducted in the ICU/ICCU Room at Tarakan Hospital, North Kalimantan, from May to June 2019. A total of 30 patients was selected by accidental sampling. The dependent variable was central venous pressure. The independent variable was the position of the patient when a central venous pressure examination was carried out, with the degree of positions which were $0^{\circ}, 15^{\circ}, 30^{\circ}$, and $45^{\circ}$. The data was obtained from observation sheet. CVP was measured by water manometer. The data were analyzed by Anova.

Results: The lowest mean CVP was achieved at $0^{\circ}(\mathrm{Mean}=15.13 ; \mathrm{SD}=5 \cdot 79)$. The highest mean CVP was achieved at $45^{\circ}(\mathrm{Mean}=18.18 ; \mathrm{SD}=5.35)$. The different mean between $\mathrm{O}^{\circ}$ and $45^{\circ}$ was statistically significant $(\mathrm{p}=0.001)$. The mean $\mathrm{CVD}$ at $15^{\circ}$ was mean $=16.35 ; \mathrm{SD}=5.73$. The mean CVD at $30^{\circ}$ was mean $=17.07 ; \mathrm{SD}=5.42$ ). The different mean between $15^{\circ}$ and $30^{\circ}$ was statistically significant $(\mathrm{p}=0.047)$.
\end{abstract}

Conclusion: The best position for perform central venous pressure is $45^{\circ}$.

Keywords: central vein pressure, intensive care, patient position

\section{Correspondence:}

Hendy Lesmana. Nursing Department, Faculty of Health, Universitas Borneo Tarakan. Email: damayanti.titha@gmail.com.

\section{BACKGROUND}

Central Venous Pressure (CVP) or central venous pressure is an invasive method of hemodynamic monitoring. CVP is often used in intensive care, especially in patients who experience impaired fluid balance, heart failure, evaluation of therapeutic response and media for therapy or hypertonic fluid. In the UK around 200,000 central venous catheters are inserted (inserted) every year (Jevon and Ewens, 2009), as well as in
Indonesia, although statistically, there are no definite data mentioning the number of central venous catheter insertions each year, but central venous catheter insertion often found especially in intensive care rooms such as Intensive care units, Cardiovascular Care Units, High Care Units, Intermediate Care Units, so it is expected that nurses who are in intensive care have good knowledge and skills in measuring and monitoring central venous pressure. Monitoring central venous pressure can be useful 
in assessing heart function, circulating blood volume, vascular tone and patient response to therapy. However, measurement of central venous pressure can be influenced by a number of factors that can refract the measurement results, including the use of vasopressor drugs, gravity (patient position), device factors (clogged catheters and improper catheter tip locations), measurement error factors (incorrect calibration, inconsistent measurement procedures and respiratory oscillations) and in patients who have ventilators installed (especially the Positive End Expiratory Pressure mode).

The hemodynamic condition of patients during treatment in the ICU was always changing (unstable), so serial monitoring of central venous pressure is needed and in the patient's position, it must be constant and must use the same reference point (mid-axilla) (Jevon and Ewens, 2009). The obstacle faced by nurses in the ICU treatment room was that the patient's position sometimes cannot be constant. This was because the condition of the patient sometimes changes and must change the position (degree) of the bed from the patient.

Changes in the position of these patients have an impact on changes in the results and meanings of the central venous pressure. Based on the theoretical description and facts of the problem that the author found in the ICU related to the measurement of central venous pressure, the authors were interested in conducting the study entitled "Analysis of changes in the patients position of $0^{\circ}, 15^{\circ}, 30^{\circ}$, and $45^{\circ}$ on the results of central venous pressure measurements"

\section{SUBJECTS AND METHOD}

\section{Study Design}

This was a quasi-experimental study using a post test without control group design method with repeated measures. This study was conducted in the ICU/ICCU Room at Tarakan Hospital North Kalimantan Province during May to June 2019.

\section{Population and Sample}

Population in this study was patients who were installed in the central veins catheter which required monitoring of central venous pressure in the ICU/ICCU room. Total 30 patients were selected for this study by accidental sampling.

The study subject consisted of 1 group with 3 treatments, at first, the patient was at o degrees after 5 minutes of CVP measurement, then the patient was positioned 15 degrees and CVP measurements were performed (after 5 minutes), the patient was positioned in 30 degrees (after 5 minutes) CVP measurements were carried out, and finally the patients were positioned in 45 degrees (after 5 minutes) CVP measurements were taken.

\section{Study Variables}

The dependent variable was central venous pressure. The independent variable was the position of the patient when a central venous pressure examination was carried out, with the degree of positions which were $0^{\circ}$, $15^{\circ}, 30^{\circ}$, and $45^{\circ}$.

\section{Study Instrument}

The study instrument used observation sheet changes in position with the results of CVP measurements, CVP measurements with water manometer techniques so that the unit of measurement used $\mathrm{cmH}_{2} \mathrm{O}$.

\section{Data Analysis}

The data were analyzed by Anova.

\section{Research Ethics}

This research was only carried out after obtaining an ethical clearance from an authorized ethics committee at the Mataram Faculty of Medicine with a letter number: 283/UN18.8/ETIK/2017. 


\section{RESULTS}

Based on table 1 , the results of repeated ANOVA tests to four positions showed the value of $\mathrm{p}=0.001$, therefore, there was an effect of changes in positions of $\mathrm{O}^{\circ}, 15^{\circ}, 30^{\circ}$, and $45^{\circ}$ on CVP measurements.

1. The effect of change of position $0^{\circ}, 15^{\circ}, 30^{\circ}$, and $45^{\circ}$ on CVP value

Table 1. The effect of change of position $0^{\circ}, 15^{\circ}, 30^{\circ}$, and $45^{\circ}$ on CVP value

\begin{tabular}{lcc}
\hline \multicolumn{1}{c}{ Patients Position in Bed } & Mean \pm SD & p \\
\hline $0^{\circ}$ Position & $15.13 \pm 5.79$ & 0.001 \\
$15^{\circ}$ Position & $16.35 \pm 5.73$ & 0.001 \\
$30^{\circ}$ Position & $17.07 \pm 5.42$ & 0.001 \\
$45^{\circ}$ Position & $18.18 \pm 5.35$ & 0.001
\end{tabular}

Based on table 2, all showed statistically significant so there were differences in the results of measurement of central venous pressure between the position of patient $\mathrm{O}^{\circ}$

Table 2. Comparison of CVP Value at $0^{\circ}$ Positions on Position $15^{\circ}, 3^{\circ}$, and $45^{\circ}$

\begin{tabular}{lcc}
\hline $\begin{array}{l}\text { The Comparison of } \\
\text { Patients Position }\end{array}$ & Mean Difference 95\% CI & $\mathbf{p}$ \\
\hline $\mathrm{O}^{\circ} \mathrm{vs} 15^{\circ}$ & $1.22(2.06-0.37)$ & 0.006 \\
$\mathrm{O}^{\circ} \mathrm{vs} 30^{\circ}$ & $1.93(2.84-1.02)$ & 0.001 \\
$\mathrm{O}^{\circ} \mathrm{vs} 45^{\circ}$ & $3.05(3.91-2.19)$ & 0.001 \\
\hline
\end{tabular}

\section{$0^{0}$ CVP Position}

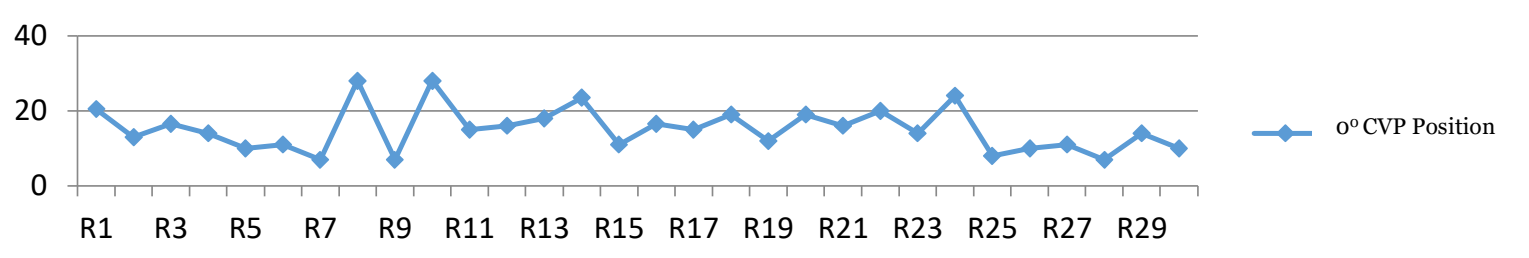

Figure 1. CVP Value Chart in $0^{\circ}$ Positions

Table 3. Comparison of CVP Value at $15^{\circ}$ Positions on Position $0^{\circ}, 3^{\circ}$, and $45^{\circ}$

\begin{tabular}{lcc}
$\begin{array}{l}\text { The Comparison of } \\
\text { Patients Position }\end{array}$ & Mean Difference \\
\hline $15^{\circ} \mathrm{vs} 0^{\circ}$ & $1.22(0.37-2.06)$ & $\mathbf{P}$ \\
$15^{\circ}{\mathrm{vs} 30^{\circ}}^{0.72(1.42-0.01)}$ & 0.006 \\
$15^{\circ} \mathrm{vs} 45^{\circ}$ & $1.83(2.76-0.91)$ & 0.001 \\
\hline Table 3 showed a significant difference. & position $15^{\circ}$ vs position $45^{\circ}$, this was \\
This was shown by the three comparisons & indicated by the value of p $=0.001$. The \\
of these positions statiscally significant. & distribution of CVP values to respondents \\
Among the three comparisons, the most & with position $15^{\circ}$ can be seen in figure 2 \\
significant difference was in the ratio of & below.
\end{tabular}




\section{$15^{0}$ CVP Position}

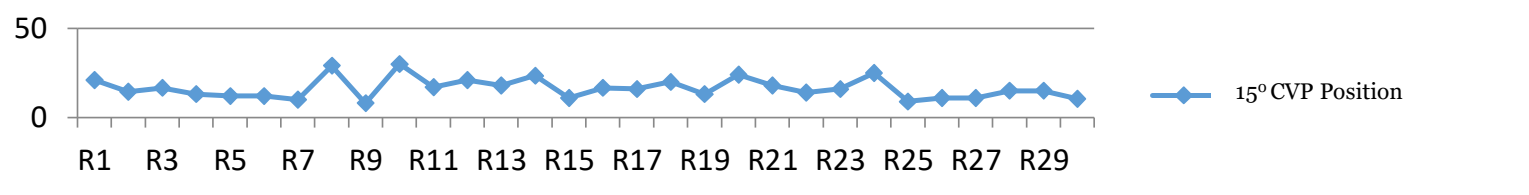

Figure 2. CVP Value Chart in $15^{\circ}$ Positions

Table 4. Comparison of CVP Value at $3^{\circ}$ Positions on Position $0^{\circ}, 1^{\circ}$, and $45^{\circ}$

\begin{tabular}{lcc}
\hline $\begin{array}{c}\text { The Comparison of } \\
\text { Patients Position }\end{array}$ & Mean Difference 95\% CI & $\mathbf{p}$ \\
\hline $30^{\circ} \mathrm{VS} \mathrm{O}^{\circ}$ & $1.93(1.02-2.84)$ & 0.001 \\
$30^{\circ} \mathrm{vs} 15^{\circ}$ & $0.72(0.01-1.42)$ & 0.047 \\
$30^{\circ} \mathrm{vs} 45^{\circ}$ & $1.12(1.60-0.63)$ & 0.001 \\
\hline
\end{tabular}

Table 4 showed that the three comparisons tions were statistically significant. The disof these positions showed significant differences. Three comparisons of these positribution of CVP values to respondents with position $30^{\circ}$ can be seen in Figure 3 .

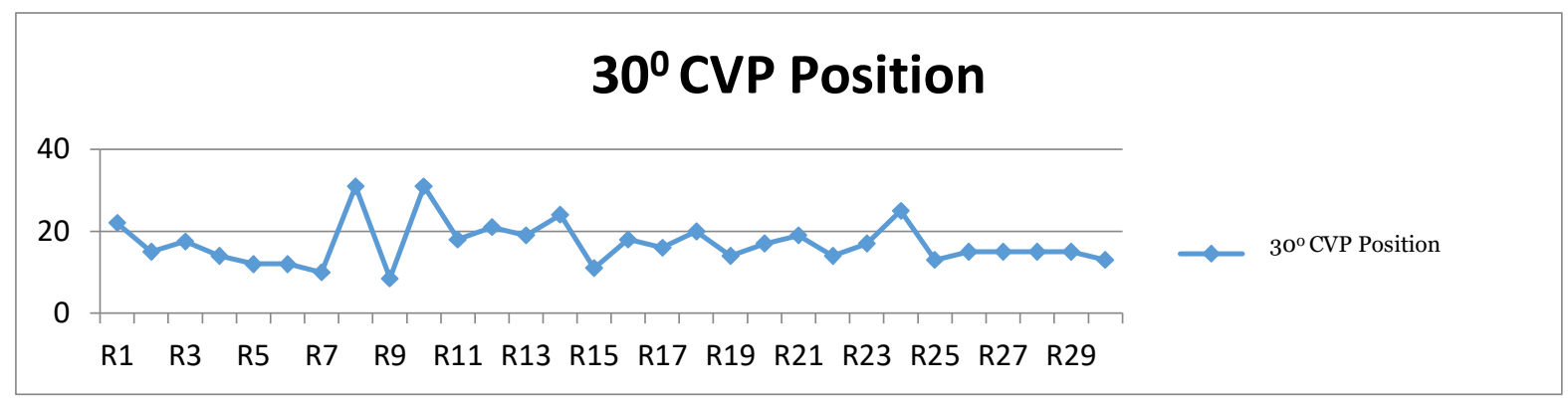

Figure 3. CVP Value Chart in $3^{\circ}$ Positions

Table 5. Comparison of CVP Value at $45^{\circ}$ Positions on Position $0^{\circ}, 15^{\circ}$, and $30^{\circ}$

\begin{tabular}{lcc}
\hline $\begin{array}{c}\text { The Comparison of } \\
\text { Patients Position }\end{array}$ & Mean Difference & $\mathbf{P}$ \\
\hline $45^{\circ} \mathrm{vs} \mathrm{O}^{\circ}$ & $3,05(2.19-3.90)$ & 0.001 \\
$45^{\circ} \mathrm{vs} 15^{\circ}$ & $1.83(0.91-2.76)$ & 0.001 \\
$45^{\circ} \mathrm{vs} 30^{\circ}$ & $1.12(0.63-1.60)$ & 0.001 \\
\hline
\end{tabular}

Table 5 showed that three comparisons tion of patients in bed previously, in the pashowed were statistically significant, there- tient with $45^{\circ}$ position compared with $\mathrm{O}^{\circ}$, fore, there was a difference in CVP values in $\quad 15^{\circ}$, and $30^{\circ}$, the distribution of CVP values the ratio of $45^{\circ}$ vs. $0^{\circ}$ position, $45^{\circ}$ vs $15^{\circ} \quad$ to respondents with position of 450 can be position, and $45^{\circ}$ vs. $30^{\circ}$ position. This was seen in Figure 1.4 below. different from the comparison of the posi- 
Indonesian Journal of Medicine (2019), 4(3): 192-200

https://doi.org/10.26911/theijmed.2019.04.03.01

\section{$45^{\circ}$ CVP Position}

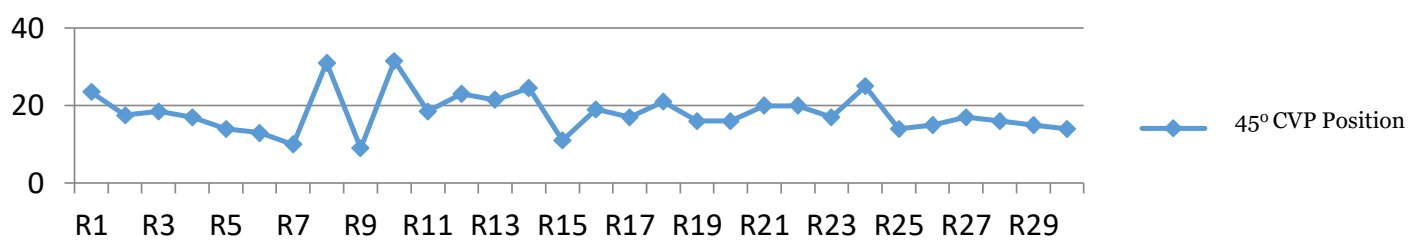

Figure 4. CVP Value Chart in $45^{\circ}$ Position

\section{DISCUSSIONS}

Monitoring of central venous pressure can be useful in assessing heart function, circulating blood volume, vascular tone, and patient response to therapy. CPV can be measured precisely with the patient in the supine position and the head elevated by $45^{\circ}$ (Magerman, 2010). The position of the patient's body when measuring the central venous pressure has an effect on the measurement results. The research conducted by Nakao, et al. quoted by Arthur, et al. (2008) stated that body position has been shown to affect the diameter, extent and shape of the inferior vena cava and this can indirectly affect central venous pressure. Study by Arthur, et al. (2008) aimed to prove the effect of inferior vena cava diameter on central venous pressure where it was found that there was a correlation between central venous pressure and inferior vena cava diameter in patients with normal ejection fraction.

Based on the results of the study, it can be concluded that the position of the client at $\mathrm{O}^{\mathrm{O}}$, the CVP value tend to be lower compared to the respondents at positions of $15^{\circ}, 30^{\circ}$, and $45^{\circ}$. Likewise vice versa on the position of $45^{\circ}$, CVP values tend to be higher compared to $\mathrm{O}^{\circ}, 15^{\circ}$ and $30^{\circ}$ positions.

Siegenthaler et al. (2014), stated that factors affecting the measurement of central venous pressure, venous return/cardiac output, total blood volume, regional vascular tone. This was in line with Morton et al. (2014), who stated that the supine position is $\mathrm{O}^{\circ}$, the gravitational force affects the whole body evenly or equally. In the lying position supination the effects of gravity on the body would decrease which made more blood flow back to the heart through the blood vessels. If the blood returned more to the heart, then the body can pump more blood every beat. This mean that the heart rate was needed a minute to fulfill blood needs, oxygen and nutrients would be less.

In the lying position, the blood was back against the force of gravity. It can be seen that while working in a standing position, the contents of the stroke increased linearly and reached the highest score of $40 \%$ to $60 \% \mathrm{VO} 2$ maximum. $\mathrm{VO} 2 \mathrm{Max}$ was the maximum volume of $\mathrm{O} 2$ that was processed by the human body during intensive activities. In the lying position, in a state of rest the key content approaches the maximum value, while there was only a slight increase in work. Wong (2000) stated that any increase of 100 from the head would cause a decrease in intracranial pressure of $1 \mathrm{mmHg}$. This increase in head position would increase the back flow of blood from the brain towards the heart through the superior vena cava, so that there was an increase in the amount of blood returning to the heart which increased volume and also affected central venous pressure. 
The value of lying in a resting position was almost the same as the maximum value obtained at work with a standing position. The number of buds in male adults has a variation between 70 to $100 \mathrm{ml}$. The greater the work intensity (exceeding the $80 \%$ limit of work capacity), the smaller the contents, this was due to shortening of diastolic filling time due to increased heart rate (if it reached $180 /$ minute, then 1 cycle of heart rate lasted only 0.3 seconds and diastole filling was part of 0.3 seconds (Guyton, 2002).

Changes in body posture from the supine position to the upright position change caused mechanical changes due to the effects of gravity on the circulatory system and changes caused by the nerve reflex response produced. Changes in body posture from $30^{\circ}$ and $60^{\circ}$ and $0^{\circ}$ Head Up Till. Cardiovascular response to changes in position $30^{\circ}$ showed a lower Cardiac Index value compared to o positions, a baroreseptor mechanism of peripheral arteries as peripheral vasoconstriction which maintained pressure from decline. However, the change in position to $30^{\circ}$ resulted in a reduced stroke volume due to reduced venous return and reduced preload. Associated with changes in position with respect to circulation, the change in position $30^{\circ}$ also raised circulation values on the periphery, where the value was measured by using the CAVI value (Cardiac Ankel Vascular Index) which functioned as an arterial stiffness index to estimate afterload. In addition, in the phase of influence of orthostatic stress, an increase in receptor gain contributed to the hyperactivity of sympathetic nerves and ultimately increased peripheral resistance (Zwain et al., 2013).

$45^{\circ}$ angle position was a position that increased cardiac and ventricular output and facilitated elimination of vecal and voiding, in this position the bed was raised by $45^{\circ}$ and the client's knees were slightly elevated so that there were no circulatory barriers to extremity (Potter and Perry, 2005). The supination position of $45^{\circ}$ tends to be more stable, this was because the sympathetic vasoconstrictor system was stimulated and the signals were transmitted simultaneously through the skeletal nerves to the skeletal muscles of the body, especially the abdominal muscles. This situation would increase basic tone, the muscles suppress the entire abdominal vein to help expel blood from the vascular abdominal reserve of the heart. This made the amount of blood available to the heart to pump up to increase. The entire response was called the abdominal compression reflex (Guyton and Hall, 2002).

The results of this study indicated the highest difference in central venous pressure in the ratio of $0^{\circ}$ vs $45^{\circ}$ and the lowest ratio of $15^{\circ} \mathrm{vs} 30^{\circ}$. Overall, there were significant differences in the value of the central venous pressure at $00,15^{\circ}, 30^{\circ}$ and $45^{\circ}$. The results of this study indicated that the further changes in the initial position with the current position of the respondent would cause changes in the higher CVP value, on the contrary, the smaller change in position would cause small changes to the results of CVP measurements. This was in line with Siegenthaler et al. (2014) who states that venous pressure is affected by gravity. This caused the pressure on the vessels above the heart to decrease and those below the heart would increase. The magnitude of the effect of gravity was $0.77 \mathrm{mmHg} / \mathrm{cm}$ vertical distances above or below the heart in blood with normal density. Therefore, in adult who were in an upright position, when the mean arterial pressure in the heart was $100 \mathrm{mmHg}$, the mean pressure on the large artery in the head $(50 \mathrm{~cm}$ from the heart) was $62 \mathrm{mmHg}$ while the pressure on the large arteries was in the foot $(105 \mathrm{~cm}$ 
below the heart), was $180 \mathrm{mmHg}$. The similar thing applied to venous pressure. So it can be concluded that with changes in position there was a change in central venous pressure.

Another thing that needed to be considered in nursing if the patient was changed from using a CVP water monitoring system to a pressure transducer system, the nurse must remember that the normal values in the two systems were different. CVP measured by water manometers which normally range from 5 to $8 \mathrm{~cm} \mathrm{H} 20$ and CVP measured by transducer pressure normally ranges from o to $6 \mathrm{mmHg}$. The value was different because merquri was heavier than water. To change the value in cmHo2 to $\mathrm{mmHg}$, the value in $\mathrm{cmH} 2 \mathrm{O}$ was divided by 1.36 . The tendency of the most significant value was shown when it was associated with the patient's cardiovascular dysfunction and the response to intervention.

Decreased CVP values indicated hypovolemic status that often required administration of fluids. Responses anticipation of fluid therapy was an increase in CVP. In the same way, diuretic therapy decreased intravascular volume and was associated with a decrease in CVP value. Low CVP values or decreased CVP values can also be associated with vasodilatation due to sepsis or vasodilatation drugs, both of which caused relative hypovolemic because blood volume did not change. More precisely, the intravascular space became bigger according to the patient's blood volume (Convertino et al., 2001)

The enhancement of CVP value of patients can be caused by a number of complex and interconnected factors, each of which required precision. Right ventricular failure and mechanical ventilation were two common causes of increasing CVP values. Excessive intravascular volume and hypervolaemia rarely cause an increase in CVP values. Mechanical ventilation increased intra-thoracic pressure, which was passed on to the vascularization of the lungs, heart and large blood vessels. The CVP value can be directly affected by this pressure. The CVP value can also increase because intrathoracic pressure suppresses large blood vessels. The CVP value can be directly affected by intrathoracic pressure pressing on the pulmonary arteries resulting in resistance to the right ventricular back pulmonary blood flow, right atrium and vena cava. In severe cases, increased intrathoracic pressure caused by mechanical ventilation resulted in severe right ventricular dysfunction, increased intrathoracic pressure caused by increased mechanical ventiation due to a decrease in blood flow up and blood supply and pressure in the right atrium and vena cava (Randazzo et al., 2003).

Right ventricular failure due to coronary artery disease or left ventricular failure, can cause an increase in CVP value. The inability of the right ventricle to pump blood through pulmonary vascularization due to injury or myocardial infarction caused an increase in volume and pressure in the right atrium and vena cava. Left ventricular failure can increase CVP values due to blood pressure and volume which caused congestion of pulmonary vascularization and disrupted blood flow from the right ventricle which resulting in right ventricular dilation and subsequent failure. Increased pressure was reflected back to the right atrium and vena cava. For example, the interventions were aimed at increasing blood flow upward by increasing ventricular contractility and reducing intravascular blood volume, thus causing a decrease in CVP measurements and a decrease in the value of this CVP was a sign of effectiveness of therapy (Convertino et al., 2001). The results of CVP measurements should be linked to other clinical 
examinations/observations, such as auscultation of breath sounds, heart rate and respiratory frequency, EKG examination results, distention of the jugular vein and urine output. Patients who experienced sepsis may have low CPV values due to an increase in heart rate but there were no other clinical symptoms. The value of CPV did not have an accurate meaning, but when it was used in conjunction with other clinical data, the value of CVP would be very useful in the management of predicting the clinical course of the patient's disease.

In this study, it showed that the gravity factor (patient position) in the measurement showed a difference in good position from $0^{\circ}, 15^{\circ}, 30^{\circ}$ and $45^{\circ}$ position, there was an increase in the value of the measurement of central vein. The huge change in the position of the respondent from the initial position would cause a large change in the results of the CVP measurement. The biggest change in position was found in changes in $0^{\circ}$ vs $45^{\circ}$ and the smallest change occurred from $15^{\circ}$ vs $30^{\circ}$. But overall, the change in the position of the patient in bed from $\mathrm{O}^{\circ}$ position to $15^{\circ}, 30^{\circ}$, and $45^{\circ}$ positions, changes from $15^{\circ}$ to $\mathrm{O}^{\circ}, 30^{\circ}$, and $45^{\circ}$ positions, changes in $30^{\circ}$ to $0^{\circ}, 15^{\circ}$, and $45^{\circ}$ positions, and changes in $45^{\circ}$ to $\mathrm{O}^{\circ}, 15^{\circ}$, and $30^{\circ}$ positions caused changes in the measurement results of CVP.

\section{AUTHORS CONTRIBUTION}

Hendy Lesmana collected data and processed data analysis. Maria Imaculata Ose examined the conceptual framework and suggested the methodology. Rahmatuz Zulfia and Kurniaty Ika Sari Tobing interpreted the results of data analysis.

\section{FUNDING AND SPONSORSHIP}

This study was funded by the Head of the Institute for Research and Service to the
Borneo Tarakan University community.

\section{ACKNOWLEDGEMENT}

The author would like to say thank you to the Head of the Institute for Research and Service to the people of Borneo Tarakan University who had supported the funds so that this study can be finished.

\section{CONFLICT OF INTEREST}

There was no conflict of interest.

\section{REFERENCE}

Arthur ME, Landolfo C, Wade M, Castresana (2009). Inferior vena cava diameter (IVCD) measured with transesophageal echocardiography (TEE) can be used to derive the central venous pressure (CVP) in anesthetized mechanically ventilated patients. Journal of CV Ultrasound \& Allied Tech.

Convertino VA, Ludwig DA, Elliott JJ, Wade CE, Assistance T, Owens R (2001). Evidence for central venous pressure resetting during initial exposure to microgravity, 2021-2028.

Guyton AC, Hall JE (2014). Buku Ajar Fisiologi Kedokteran (Textbook of Medical Physiolog). Edisi 12. Jakarta. EGC.

Jevon P, Ewens B, Pooni JS (2009). Pemantauan Pasien Kritis (Critical Patient Monitoring). Edisi ke II. Erlangga Medikal Series. Jakarta.

Magerman Y (2010). Central Venous Pressure. Lecturer Notes, 16.

Morton PG (2014). Keperawatan Kritis Pendekatan Asuhan Holistik (Critical Nursing Holistic Care Approach).

Potter PA, Perry AG (2005). Buku Ajar Fundamental Keperawatan: Konsep, Proses, dan Praktik (Textbook of Fundamental Nursing: Concepts, Process- 
Indonesian Journal of Medicine (2019), 4(3): 192-200

https://doi.org/10.26911/theijmed.2019.04.03.01

es, and Practices). 4(2). Jakarta. EGC

Randazzo MR, Snoey ER, Levitt MA, Binder

K (2003). Accuracy of Emergency Physician Assessment of Left Ventricular Ejection Fraction and Central Venous Pressure Using Echocardiography, 10(9). https://doi.org/10.1197/S1069-6563(03)00317-8.

Siegenthaler N, Giraud R, Saxer T, Courvosier DS, Romand J, Bendjelid $\mathrm{K}$ (2014). Haemodynamic Monitoring in the Intensive Care Unit: Results from a Web-Based Swiss Survey, 2014. https://doi.org/10.1155/2014/129593

Wong F (2000). Prevention of Secondary Brain Injury. Critical Care Nurse. 20(5): 18-27.

Zwain AA, Al Esawi RW, Al-Dejeli AA (2013). Cardiac index (CI) versus cardio ankle vascular index (CAVI) at different degrees of head-up tilt (HUT) in healthy subjects. Open Journal of Molecular and Integrative Physiology, 3(2): 71. 